\title{
Study on the Reform of Innovative Experimental Teaching Mode Based on Fischer Robot
}

\author{
Huang Zhicheng ${ }^{1, a}$, , Liu Liya ${ }^{1,}$ a and Li Zelun ${ }^{2, b}$ \\ ${ }^{1}$ College of Mechanical and Electronic Engineering, Jingdezhen Ceramic Institute, Jingdezhen, Jiangxi \\ 333001, China \\ ${ }^{2}$ College of Mechanical and Dynamic Engineering, Chongqing University of Science and Technology, \\ Chongqing, China \\ a huangwu555@sina.com, binstru@163.com \\ *corresponding author
}

Keywords: Fischer robot, Electromechanical, Experiment teaching, open innovation

\begin{abstract}
According to the characteristics of experimental teaching in colleges and universities, due to the good combination of detachable splicing performance of the Fischer robot, it is widely introduced into the classroom and its creativity is maximized. Through the integration of the original second classroom teaching and experimental resources, further enhance the mechanical and electrical innovation experiment of the Fischer robot. Innovative experimental teaching reform has attracted more students to participate in innovation experiments, the formation of a real "open" experimental teaching.
\end{abstract}

\section{Introduction}

China higher education has entered a period of rapid development, which requires that we should comprehensively promote quality education in higher education, improve the scientific quality of college students, cultivate the innovative ability of college students, and create a large number of innovative talents to meet the needs of the rapid development of modernization ${ }^{[1-4]}$.In recent years, innovative education for college students, many colleges and universities are equipped with different types of teaching robot, and has been put into use ${ }^{[5-11]}$.The Fischertechnik combinatorial model is a teaching creative robot invented by German inventor Dr. Arthtlr Fischer ${ }^{[12-13]}$.It represents many areas of high technology, by educators around the world attention and thinking. A large number of well-known companies such as Germany's Siemens, Germany's BMW and IBM have used the Fischer fish model to demonstrate their production lines. In addition, colleges and universities in Germany and the United States have used Fischer robots as teaching robots for the teaching and experiment of mechanical courses ${ }^{[14-16]}$.Nanjing University of Science and Technology made use of Fischer robot to conduct experimental teaching of undergraduate

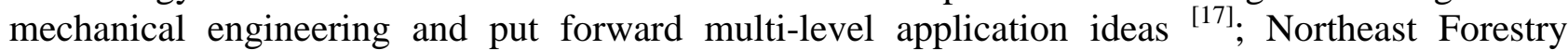
University robot teaching using Fischer robotics ${ }^{[18]}$; Southwest University of Science and Technology, Liaoning Industrial University and Huaiyin Institute of Technology and other colleges and universities in the form of training week Fischer robot for innovative experiments [19${ }^{20]}$.Jingdezhen Ceramic Institute school of Mechanical and Electrical equipped with more than 30,0000 Yuan Fischer robot creative combination model, and the establishment of a mechanical innovation laboratory. In short, the Fischer robot not only can train student's ability to solve specific problems, but also can develop student's Hands-on ability and ability to innovate, widely by many colleges and universities at home and abroad attention.

\section{Fischer robot experiment teaching implementation plan}

In this paper, we propose an open innovation experiment program based on the Fischer teaching robot, develop the experimental system of the Fischer teaching robot and further expand to other 
types of mechanical innovation experiments, develop innovative experimental projects, write innovative experimental instructions and teaching materials, and create open innovation Experimental teaching platform; combined with teaching, practice, scientific research and graduation project (dissertation) and science and technology competition, the reform of the existing mechanical and electrical class week experimental and practical experimental teaching mode.

\subsection{Combining with teaching}

Fischer robot fosters students' interest and sense of innovation to help students digest, master and consolidate knowledge. Taking "hydraulic control system" as an example, when explaining knowledge of hydraulic cylinder, hydraulic basic circuit and pneumatic, etc., the pre-built pneumatic robot can be put on the podium and the theory can be realized in kind. This not only helps students Digest knowledge, but also stimulate students' interest in learning. At the same time, students can also take the initiative in the classroom, put forward a variety of programs for the same problem, and then discuss one by one, to achieve the teaching of "student-oriented" change. The experiment with the students can put their own programs through the Fischer robot creative combination model to achieve, which consolidate the knowledge learned at the same time, they also cultivate their own sense of innovation and innovation.

\subsection{Combining with practice}

The use of Fischer robot mechanical and electrical courses innovation practice weeks, curriculum design, in order to achieve the mastery of knowledge and comprehensive application. In order to improve students' creative quality, students can be provided with the Fischer-fish creative combination model, which gives students the maximum imagination space to formulate practical plans and put them into practice. Finally, they can check the practical effect through the reply. In the past, due to the time, some subjects in the curriculum design are difficult to complete efficiently and satisfactorily. Taking the course design of mechatronics technology for example, students are now able to design mechatronic systems using the Fischer Industrial Robot, Fischer Mobile Robot, sensors and motors. All of these not only change the boring and tedious process of past practice, but also improve the enthusiasm and initiative of students, and realize the transformation from practice to synthesis, research and design, and finally the cultivation of quality education.

\subsection{Combined with research and graduation design (Thesis)}

Fisheye Interest Group was set up among students, and applied to research and graduation project (dissertation). To truly and completely improve the student's innovation consciousness and ability to innovate, the reform based on teaching and practice alone is far from enough, and it is also necessary to create an atmosphere of creative practice among students and to provide opportunities for innovation and practice so as to point out the surface and improve students' innovation in an allround way Quality. To this end, the school should be based on mechanical innovation laboratory, students set up innovative experimental group, the teacher is responsible for guiding the laboratory for students. In addition, in line with the teaching reform of innovative education, schools will make innovations in innovation laboratories, including: organizing laboratories to be fully open; revising experimental programs for innovation and experimental instructions; preparing mechanical innovation teaching materials; and within the scope of the conditions Try to increase and develop experimental projects for students to choose freely; the experimental projects require space for students to freely play. At the same time, graduation project, the formation of student task force, the integrated use of knowledge, to complete a larger model of electromechanical control system, so that not only train students to deal with the larger system topics ability, but also to cultivate the coordination between students And teamwork.

\subsection{Combining with technology competition}

In March each year, colleges and universities hold innovative design competitions throughout the school. The science and technology competitions, as part of the electromechanical practical courses, have the same credits for internship training. Based on the Fischer robot, students can further 
develop other types of innovative designs, design other types of robots themselves or conduct other innovative experiments to give full play to students' autonomous ability and innovative ability. Students participate in the form of free team, each team of 4-6 people, colleges and universities to each team to give some funding. In May, students submitted innovative works and conducted live defences. The professional teachers make up the review group, and make a comprehensive evaluation of the creative works and the replies made by the students, divided into qualified and unqualified. In the qualified students' creative works, the first prize, the second prize and the third prize are evaluated, award certificates are awarded and certain financial rewards are given. Excellent teams can represent schools at provincial and national innovation design competitions.

\section{Fischer robot experimental teaching mode of two changes}

\subsection{Closed mechanical and electrical experiment teaching mode to open teaching mode change}

The traditional electromechanical experiment teaching generally adopts the closed teaching mode such as the experiment of the lesson band and the training week, etc. The research of this project will provide an open and innovative experimental teaching mode for the experiment of electromechanical experiment. This project will create a teaching and experiment platform for students based on open and innovative activities. Students will be more active, informative and interesting as well as creative and cooperative in their active participation.

\subsection{Mechanical and electrical experiment examination mode change}

In Fischer robot-based innovation experiments, students can design related robots and all kinds of electromechanical systems. There is no standard answer or fixed mode for students 'design results, which can give full play to students' innovative ability. In addition, innovative experiments can be combined with science and technology competitions. After students submit their works, students will be given corresponding grades and credits according to the students' work and their defense status.

\section{Fischer Robot Innovation Experiment Classroom Implementation Effect}

In 2013, the Fischer model entered into the students' innovative experiment class. First, the students in the mechanical and electrical engineering should have a classroom teaching reform. In the early stage, about 600 students of Mechanical Design, Electrical engineering and Automation majors in Mechanical Innovation Labs. In the later period, the experimental class reform was conducted to other polytechnic students, attracting many students to enter into innovative laboratories and form a true "open" experimental teaching. The university held regular innovation and design competitions and started to promote it throughout the school. The whole school has formed a wave of scientific laboratories based on the concept of innovation, and the enthusiasm, initiative, creativity and cooperation of students in participating in innovation experiments have been significantly enhanced.

Since the implementation of the experimental teaching reform of electromechanical class, it has been tried to apply the Fischer robot to various courses as well as a series of related curriculum design, graduation project and scientific competition, which is more successful from the reflection of teachers and students. Each time the Fischer Robotics Innovation Competition always set off a wave of innovation in the hospital, not only attracting students in the Department of Electrical Engineering, but also attracted other students. At the same time in the competition, the team cooperation to cultivate the collective spirit of students.

\section{Conclusion}

Through the reform of the existing experimental model of electromechanical teaching, we have created an open and innovative experimental teaching mode, built an open experimental platform and written and completed innovative experimental instruction manuals and mechanical innovation 
teaching materials. To cultivate students 'innovative design, innovative thinking and practical ability in an important position to meet the needs of higher education for the cultivation of students' innovative abilities, to stimulate students 'creativity, motivate students to learn the initiative to develop students' ability to analyze and solve problems And teamwork skills. The introduction of Fischer robot brings a great deal of convenience and interest to experimental teaching. The experiment in class is not boring. Students actively participate in and cooperate with each other, and proactively inject innovative thinking into experimental design, which greatly improves the awareness of innovation and teamwork. Many colleges and universities have conducted experimental teaching reform, have achieved initial success. Student innovative ideas are supported and can be implemented In the experiment, the positive autonomy is strengthened, the ability to independently analyze the ability and team collaboration have also been significantly improved.

\section{Acknowledgements}

The work of this article is grateful to Jiangxi Provincial Department of Education for Teaching Reform Research Key Project (JXJG-16-11-1), Chongqing Municipal Education Reform Project (172032) and Chongqing Institute of Science and Technology Education Reform Project.

\section{References}

[1] Zhu Zhixong, Yan Xiaozhao, Xu Hailei. Mechanical and electrical specialty open innovation practice teaching mode exploration [J]. Higher Education Forum, 2008 (6): 141-143.

[2] Corvin. Literary theory of education and teaching development [M]. Beijing: Atomic Energy Press, 2004: 162.

[3] Chen Ya-men, Wang Dan, Wang Xiaoguang and so on. Cultivation of innovative ability calls for new teaching mode [J]. China Metallurgical Education, 2002 (3): 26-28.

[4] Jiang Dan-liu. Exploratory experiment led the development of research curriculum [J]. Journal of Wuxi Institute of Education, 2001, 21 (3): 63-65.

[5] Lu Qing, Zhao Ying Kai. Capacity storm personal robot applications [J]. Robotics and Applications, 2002 (1): 17-19.

[6] Cong Shuang, Qian Hui Central. The Flexible Application of Capability Storm Robot in Practice [J] .Computer Measurement and Control, 2004, 12 (4): 380-384.

[7] Wu Qingfeng, Sun Hua, Wang Yijun. Institutional innovation experiment set up research [J]. Experimental Science and Technology, 2001 (1): 99-100.

[8] Wang Chao. Mechanical innovation design experiment teaching reform discussion [J]. Equipment Manufacturing Technology, 2008 (8): 179-180.

[9] Liu Ling order, Li Guanghui, Zhou know into. Mechanical foundation of innovative experimental system [J]. Laboratory Research and Exploration, 2009, 28 (2): 100-103.

[10] Lu Chengjing. Practice and thinking on the goal and content of robotics teaching [J]. China Electrochemical Education, 2006, 12: 71-72.

[11] Wan Youhong, Jiang Guoping. Robot education and creative ability of college students to explore [J]. Journal of Electrical and Electronic Education, 2005, 27 (4): 6-9.

[12] Zhang Hai, Wang Xiaoming. FESTO MPS automation control system in the experimental teaching application [J]. Machine and Hydraulic, 2007, 35 (11): 134-136.

[13] FESTO. Modular production system handbook [M]. 1996: 10.

[14] Feng W, Yang Y. A research and realization on the Gait of the Fischertechnik hexapod bionitc robot [J]. Machine Design and Research, 2005, 21 (3): 35-38. 
[15] Ebbesmeyer P, Gausenieier, J Grafe, Designing flexible production systems with virtual reality [J]. Proceeding of the ASME 2001 Design Engineering Technical Conference and Computers and Intonations, 2001 (5): 331-335.

[16] Billinghutst M, Iiilanioto K, Kato H. Virtual Object Manipulation on a Table Top AR Environment [J]. Proceedings of the IEEE and ACM International Symposium Augmented Reality 2000 (8): 625-628.

[17] Cai Li, Guo Lu home. Multi-level application of fisheye model in undergraduate teaching [J], Laboratory Research and Exploration, 2004, 23 (7): 81-83.

[18] Xin Ying, Xue Wei, Wang Jian. Research on the Reform of Robot Course Experiment Teaching Based on the Fischer Fish Model [J], Modern Education Technology, 2009, 19 (7): 138140 .

[19] Wen Pei first, Han Manlin. Fischer innovative combination of experiments and training students ability to study learning [J], Journal of Changzhou Institute of Information Technology, 2002, 12 (1): 70-72.

[20] Xiao Xiaoping, Liao Qing. Study on the Application of Fischer Fish's Creative Combination Model in College Students' Innovative Education [J], Higher Education Research, 2006, 22 (2): 7376. 